\title{
A Filosofia de Schopenhauer na narrativa do jovem Werther de Goethe
}

\section{Schopenhauer's Philosophy in the narrative of the young Werther de Goethe}

\section{Flávio Rocha de Deus*}

Resumo: 0 presente trabalho se propõe a discorrer acerca da concepção de suicídio e suas motivações para Arthur Schopenhauer e utilizar o romance epistolar Os sofrimentos do jovem Werther como ilustração de tal percepção. Para tal seguimos o seguinte roteiro: encontrar as motivacões metafísicas do suicídio para Schopenhauer; expor as considerações do filósofo supracitado sobre o sofrimento e o amor; demostrar como ambos os fenômenos se relacionam com a atitude suicida e a partir desta ótica analisar o romance epistolar de Goethe para expor no mesmo uma ilustração da filosofia schopenhauriana.

Palavras-chave: Schopenhauer; Werther; Suicídio; Sofrimento; Amor

Abstract: The present work proposes to discuss the concept of suicide and its motivations for Arthur Schopenhauer and to use the epistolary novel The sorrows of young Werther as an illustration of such perception. To this end, we follow the following script: find the metaphysical motivations of suicide for Schopenhauer; expose the aforementioned philosopher's considerations about suffering and love; to demonstrate how both phenomena are related to the suicidal attitude and, from this perspective, to analyze Goethe's epistolary novel to expose an illustration of Schopenhaurian philosophy.

Keywords: Schopenhauer; Werther; Suicide; Suffering; Love

O amor é um precipício, a gente se joga nele, e torce para o chão nunca chegar.

(Inaura. Lisbela e o Prisioneiro)

\section{Preâmbulo}

Em seu escrito acerca da metafísica do amor, o filósofo Arthur Schopenhauer, em alguns momentos, menciona o romance epistolar de Goethe como uma ilustração de suas considerações. Nosso propósito neste trabalho será então apontar de forma mais detalhada como as considerações da filosofia de Schopenhauer se apresenta nesta obra literária.

Pensar a filosofia de forma isolada, unicamente como a busca e delimitação de conceitos, limita o viés altamente reflexivo e suas incontáveis formas de diálogos com outras áreas, dentre elas, a literatura. Pensar nos conceitos já estabelecidos por filósofos do cânone e ver suas representações em obras literárias nos permite ampliar os horizontes representativos das conclusões metafísicas de alguns autores na vida prática. A exemplos: Os escritos de Platão, $O$ cândido de Voltaire, $O$ estrangeiro de Albert Camus, Entre quatro paredes de Sartre, dentre outros. 0 que ocorre nestes casos citados é o fato de tais narrativas literário terem sido usadas pelos próprios filósofos como forma uma didática de exemplificar suas teorias, entretanto, não é impossível que terceiros desenvolvam narrativas que apresentem alto teor reflexivo ou alusivo à teoria filosófica de outrem, como é o caso que nos propomos a analisar.

Este trabalho é de caráter hermenêutico e detém como objetivo fazer associações entre as conclusões do filósofo Arthur Schopenhauer sobre o sofrimento, o amor e o suicídio e a narrativa do jovem Werther no romance epistolar de Goethe. As principais técnicas para sua

* Graduando em Filosofia pelo Departamento de Educação do Campus I da Universidade do Estado da Bahia, Salvador, BA Email: rocha.iflavio@gmail.com ORCID: https://orcid.org/0000-0002-7523-5512 
produção foram a leitura e o fichamento de textos selecionados. 0 corpus primário está definido pelo romance de Goethe Os sofrimentos do jovem Werther e a principal obra de Schopenhauer: $O$ mundo como vontade e representação, principalmente seu quarto livro, em que o mesmo se dedica a explicar de forma mais detalhada os mecanismos do sofrimento e sua supressão. 0 corpus secundário é constituído por outros textos do filósofo (Metafísica do amor, Sobre a afirmação da vontade e Sobre o suicidio) e por artigos e obras de comentadores acerca do tema principal e de temas correlatos.

\section{Werther, Tempestade e Ímpeto}

Os sofrimentos do Jovem Werther é um romance epistolar do século XVIII e possui como trama o cotidiano e os sentimentos narrados pelo protagonista que dá nome ao livro. 0 enredo gira em torno da súbita paixão de Werther por Charlotte, uma jovem já comprometida e prometida a outro homem. 0 matrimônio da amada com outro rapaz, Alberto, é o motivo de seus sofrimentos. Por já estar compromissada a outro, o que vemos durante todo o romance é o martírio do jovem Werther por estar tão próximo e ao mesmo tempo tão distante daquilo que deseja.

A obra foi escrita no período comumente denominado como romantismo: um movimento intelectual da Europa do século XVIII-XIX. Lowy e Sayre (2015) nos elucidam acerca da dificuldade existente para definir de forma conceitual o que foi este movimento, principalmente pelo caráter contraditório e abrangente do movimento que apresenta ao mesmo tempo, ou alternadamente, características de cunho "revolucionário e contrarrevolucionário, individualista e comunitário, [...], realista e fantástico, retrógrado e utopista, revoltado e melancólico, [...] ativista e contemplativo", dentre outros ${ }^{1}$. Essas particularidades se encontram tanto nas obras como nos autores. Estas nebulosidades aparentam-se como compreensíveis pela diversidade de formas no qual o movimento se manifestou na sociedade, não se limitando a literatura e a filosofia, mas também se estendendo a manifestações políticas, teológicas, historiográficas e intelectuais de cunho geral.

Apesar destas dificuldades, para os fins deste trabalho, a contragosto dos que consideram que "a refutação do pensamento das Luzes não pode desempenhar o papel de categoria espiritual unificadora" 2 do romantismo, acompanharemos tal interpretação, pois a consideramos a mais pertinente para a obra literária que protagoniza este texto. Mayos (2004) e Freitas (2004) também nos acompanham nesta interpretação ao considerarem este movimento intelectual como uma contraposição ao iluminismo, racionalismo e ao classicismo, desconsiderando e afastando-se dos valores, pretensões e discursos totalizantes e padronizadores da modernidade. Tendo sido a modernidade um momento de ideal puramente racionalista como nos aponta também o sociólogo Michel Maffesoli:

[...] a partir do século 17, a Europa seguiu a via recta, a estrada reta da razão. Quer dizer, um só valor. E para seguir a estrada reta da razão, deixou-se à beira da estrada toda uma série de bagagens inúteis - o sonho, o jogo, o simbólico, o imaginário - para ser eficaz ${ }^{3}$.

No romantismo o valor da subjetividade é potencializado em seus diversos aspectos ${ }^{4}$, esta linha reta em direção a uma vida mais apaixonada, cheia de sentimentos, anseios e

\footnotetext{
${ }^{1}$ LOWY; SAYRE, Revolta e melancolia: o romantismo na contracorrente da modernidade, 9.

2 Idem, ibidem, 29.

${ }^{3}$ BARROS, Michel Maffesoli: a pós-modernidade se orienta para "algo de anarquista", 4.

${ }^{4}$ Um dentre os muitos outros exemplos dessa supervalorização da subjetividade que vemos durante o romance, já aparece na primeira carta redigida pelo protagonista. Quando Werther admira um jardim e admite a extrema 
expressão chegou a afetar as que pareciam ser as grandes ferramentas do projeto moderno: o sujeito, a razão e o conhecimento científico. Este movimento (romantismo) surge por influência dos Sturmer, representantes de um movimento percussor nomeado como Tempestade e Ímpeto (Sturm um Drang), em homenagem a peça de Friedrich Klinger, de mesmo nome, que elevava os mesmos valores do que mais a frente viria se consolidar como romantismo: emoções, misticismo e subjetividade. O Sturm und drang, Tempestade e Ímpeto

[...] propunha a liberdade total de criação e um subjetivismo radical. Opondose aos preceitos da ilustração e aos modelos estéticos da tragédia clássica francesa, influenciado pela leitura da Arte Poética, de Aristóteles, [...] A liberdade proposta pelos Sturmer, inspirada na obra de Shakespeare e no pensamento de Rousseau, se expressava em uma linguagem teatral arrebatadora, com personagens tomados por instintos e individualidades e violência patética, verdadeiros "gênios" carregados de formação e imaginação criadora ${ }^{5}$.

A onda romântica se popularizou na Alemanha e realizou relevantes influências em áreas desde a música com Beethoven até a literatura e poesia, com Schiller e Goethe.

A história do jovem Werther começa com sua ida para um vilarejo tranquilo. Feliz com a beleza natural que o cerca e pela sua boa relação com os moradores do local, seu deslumbre e seu tormento tem inicio quando a caminho de um baile conhece Charlotte, mulher esta a quem a beleza lhe cativou de imediato e suas particularidades de humor, gosto e personalidade completaram o fascínio por completo. Mesmo sabendo de seu comprometimento com outro rapaz, Werther manteve-se por perto e nutrindo de forma constante sua paixão.

Cada dia a mais que passava ao lado de Charlotte, sua admiração por ela aumentava, aumentando consequentemente seu desejo, que por não conseguir se realizar tornava-se também seu grande sofrimento. Eventualmente o protagonista tenta se afastar do casal indo trabalhar em outra cidade, entretanto, eventualmente retorna para o convívio de Charlotte e Alberto. Em 10 de setembro de 1771 ele partiu para esquecê-los, mas nove meses depois, em 18 de junho de 1772 ele fraquejou e admitiu mais uma vez, em suas cartas, que a única coisa que ele queria é estar perto de Charlotte e retorna para o vilarejo.

Ao retornar a cidade, Charlotte e Albert continuam tendo um bom casamento, o que acaba completamente com as esperanças de Werther. Já em estágios altos de desilusão e tristeza, Werther, durante uma de suas visitas, não se contêm e avança em Charlotte para beijá-la. Com a total recusa e repreensão do seu ato por aquela que deseja, Werther planeja e executa seu suicidio.

\section{Schopenhauer e os mecanismos do sofrimento e do amor de Werther}

\footnotetext{
beleza do mesmo, destitui da criação do belo o domínio da técnica, sendo a criação bela uma pura expressão dos sentimentos em contato com mundo. Neste caso a objetividade da razão é desacreditada como farol do espirito, sendo substituída neste papel pela subjetividade das emoções. "O jardim é simples e logo na entrada percebe-se que aquilo não foi obra de um jardineiro especializado, mais sim de um coração sensível que queria gozar do prazer de estar consigo mesmo". (Goethe, Os sofrimentos do jovem Werther, 14). Encontramos a criação e belo desvinculado dos padrões artísticos e da técnica e passa a ser visto como uma expressão do interior do sentimental. Podemos ver outros momentos de superestima da subjetividade e dos sentimentos em particular na carta de 30 de maio de 1771 no comentário acerca da criatividade e criação artística; nas cartas de 30 de maio, 16 de julho, 24 de julho, 30 de julho do mesmo quando expõe as limitações da linguagem para expressar sentimentos sublimes e em uma sutil critica a racionalidade contida na carta de 11 de junho (1771).

${ }^{5}$ FREITAS, A conjunção de Fiesco em Gênova: história, tempestade e ímpeto na cena do jovem Schiller, 20.
} 
Werther se suicidou, pois sofria, entretanto, apenas a existência do sofrimento não pode justificar o ato, afinal sofrimento e dor são fenômenos intrínsecos a nossa vida, como nos afirma o próprio Schopenhauer, a vida oscila constantemente "como um pêndulo, para aqui e para acolá, entre a dor e o tédio" (W I, 401). Já que não é apenas a existência do sofrimento que nos orienta ao suicidio, devemos entender que existem diferentes tipos de sofrimento, especificamente gradações do sofrimento, dos mais toleráveis aos mais agonizantes. Então, o que constitui os sofrimentos mais intensos? Aparentemente a manifestação do querer-viver, da vontade, do desejo.

Schopenhauer, filósofo popularmente conhecido pelas suas considerações pessimistas acerca da vida, reafirmando sua herança platônica, com a influência kantiana e sua admiração pela filosofia indiana, vê a realidade de forma dual, sendo constituída por duas facetas: Vontade (Wille) e Representação (Vorstellun). Seus escritos pessimistas acerca das ocorrências cotidianas são uma forma didática de demostrar como a sua metafísica da Vontade se apresenta no mundo dos fenômenos ${ }^{6}$.

Reconhecerá a mesma vontade como essência mais intima não apenas dos fenômenos inteiramente semelhantes ao seu, ou seja, homens e animais, [mas também na] força que vegeta e palpita na planta [...] que forma o cristão, que gira a agulha magnética para o polo norte, [...] a própria gravidade que atua poderosamente em toda matéria [...] tudo isso é diferente apenas no fenômeno, mas conforme sua essência em si é para se reconhecer como aquilo conhecido imediatamente de maneia tão intima e melhor que qualquer outra coisa e que, ali onde aparecer de modo mais nítido chama-se Vontade. (W I, 168)

[...] para que tomemos conhecimento de um objeto, é necessário, em primeiro lugar, que nossa inteligência relacione cada impressão que nosso corpo recebe a uma causa, que ela transporte essa causa para um lugar do espaço de onde parte o efeito experimentado e que, assim, ela reconheça a causa como efetiva, como real, como um representação do mesmo tipo que nosso próprio corpo. (W I, 148)

De acordo com Schopenhauer, tudo que acontece na natureza ocorre pela manifestação da Vontade, a coisa-em-si, essência primeira de toda realidade, que de forma livre, irracional, constante, onipresente e incontrolável é responsável por todas as ocorrências do mundo ${ }^{7}$. Já a representação é a forma como nosso intelecto apreende a Vontade, é a coisa-em-si em relação ao sujeito ${ }^{8}$, pois tudo "que pertence e pode pertencer ao mundo está inevitavelmente

\footnotetext{
${ }^{6}$ Cacciola (1994, p. 28) destaca que a filosofia de Schopenhauer já se apresenta no título de sua obra principal $O$ mundo como vontade e representação (Die Welt als Wille und Vorstellung), pois aqui não é dito o que o mundo é, mas como ele se apresenta.

7 Essa irracionalidade da substância primeira da existência é o maior destaque na filosofia schopenhauriana, sendo um rompimento com o status quo filosófico do ocidente, que até então ordinariamente concebia a razão e racionalidade em primeiro plano.

80 que temos aqui é uma influência mais direta da filosofia Kantiana. Para Kant, a realidade também se apresenta de forma dual estando dividida como mundo numênico e mundo fenomênico. 0 "mundo" numênico é o mundo metafísico das coisas-em-si, em que não aparecem de nenhuma forma a percepção do sujeito cognoscente, pois ele não pode ser captado pelas intuições puras que são o espaço e o tempo. Segundo o mesmo não podemos saber absolutamente nada sobre o mundo numênico, ou ao menos não conseguimos ter informações sobre ele de modo direto. 0 que podemos conhecer é o mundo fenomênico que experienciamos através dos sentidos através das formas a priori da sensibilidade, condições necessárias e universais para todas as formas de percepção possíveis. Kant rompe com a tradição ao estabelecer isto, pois, ao caracterizar o conhecer como a capacidade de raciocinar através das impressões originárias, qualquer objeto metafísico, como não pode ser experienciado pela sensibilidade, não pode ser conhecido. É neste ponto, na inacessibilidade do conhecimento humano a coisa em si que Schopenhauer rompe com a filosofia kantiana, pois o que Kant concebia como inacessível ao conhecimento, Schopenhauer considerou como algo passível de ser entendido, tendo o
} 
investido desse estar-condicionado pelo sujeito, existindo apenas para este" (W I, 44). Para Schopenhauer, na representação, a imagem que se revela não revela nela mesma a essência verdadeira, o que ela é em sí, sendo a apenas uma ilusão, a parte exterior da realidade que se apresenta ao sujeito cognoscente.

Apesar de ser única e absolta, a Vontade se manifesta nos entes existentes de diferentes formas. Nos seres vivos, em particular, ela se manifesta através do querer-viver pela preservação do individuo e no desejo sexual pela preservação da espécie.

Vimos na natureza [...] que a essência Íntima dela é um esforço interminável, [...] Querer e esforçar-se são sua única essência, comparável a uma sede insaciável. A base de todo querer, entretanto, é necessidade, carência, logo, sofrimento, ao qual consequentemente o homem está destinado originariamente pelo seu ser. (W I, 401)

Como nos diz Brum (1998) é justamente a condição instransponível da Vontade, que a tudo governa que leva Schopenhauer a um pensamento pessimista. Para o filósofo alemão, o sofrimento é todo obstáculo que se encontra entre nós e a realização de nossos desejos. 0 problema é que segundo o mesmo, os homens estão condicionados ao querer, e este querer inerente a existência nos orienta a frustração pela não realização de nossas vontades ou ao inevitável tédio após a conquista de nossos desejos, nos localizando em um ciclo continuo e interminável de desejo, que desagua no sofrimento ou tédio, que nos orienta a outro objeto de desejo, que também está fadado ao mesmo fim que o anterior e assim repetidamente. Neste estudo do sofrimento, Schopenhauer condiciona o desejo na natureza da vida, e relaciona o desejo ao sofrimento, em seus mais diversos níveis, sendo o próprio desejo uma via de mão única a qual não se pode regredir. "Ao subir a escada da expectativa de realizações dos desejos não existe a opção de descer [...] gradualmente, degrau por degrau, só existe a queda livre, e quanto maior a altura maior é a queda (o sofrimento) do indivíduo" 9.

Quando lhe falta o objeto do querer, retirado pela rápida e fácil satisfação, assaltam-lhe vazio e tédio aterradores, isto é, seu ser e sua existência mesma se lhe tornam um fardo insuportável [...] após o homem ter posto todo sofrimento e tormento, no inferno, nada restou para o céu senão o tédio (W I, 401).

Sendo o homem a manifestação da Vontade na natureza com maior intelecto é ele também o que está mais exposto ao sofrimento já que a "proporção que o conhecimento atinge a distinção e que a consciência se eleva, aumenta o tormento" (W I, 399). Aparentemente, os animais não humanos vivem em um eterno presente, continuo nas intuições e sensações imediatas, na qual o sofrimento é muito mais caracterizado pelas carências fisiológicas do que, como é no caso dos homens, pela rememoração de sofrimentos passados e imaginação de desejos futuros.

Esta possibilidade de intuir ideias cria extensões do presente que permite projetar o futuro e remoer o passado: um sofrimento decorrido não por dores imediatas do presente, mas por ideais do intelecto. Em Schopenhauer, a forma de não sofrer é não querer, se retirar do ciclo do sofrimento através da mortificação da vontade ${ }^{10}$. Schopenhauer "nos mandaria a

próprio corpo como objeto de conhecimento. Há também a possibilidade de ter sido fortemente influenciado pelo conceito do véu de Maia, oriundo da filosofia indiana que também concebendo a realidade como dual, enxerga a existência de um véu ilusório que nos afasta da verdadeira realidade.

${ }^{9}$ DEUS, Schopenhauer e o sofrimento, 117.

10 É válido destacar que apesar de colocar a mortificação da vontade como principal caminho para a fuga do sofrimento, Schopenhauer também percebe a possibilidade de uma fuga através da arte, mesmo que seja uma fuga momentânea. A arte para Schopenhauer encontra-se em um local especial, pois enquanto a ciência e a filosofia se limitam às escarças possibilidades do conceito, a arte tem como tarefa a intuição, que é superior por 
uma farmácia para comprar pílulas de ascetismo, que seriam conseguidas através de ações de negação do desejo como a castidade, pobreza e jejum voluntários e intencionais" 11, entretanto, como o mesmo reconhece, essa capacidade de mortificar a vontade é algo de indivíduos raros, os ascetas, que aparecem no mundo com a mesma frequência que trevos de quatro folhas.

Na leitura do romance de Goethe, podemos ver que tal determinação da filosofia de Schopenhauer se faz presente. Se dividirmos a narrativa no meio, podemos ver que na visão schopenhauriana do desejo, Werther na primeira parte está subindo uma montanha, cujo topo representa a realização de seu desejo, e seu caminho de escalada representa o seu desejar acompanhado da esperança, esta alegria surgida da ideia de uma coisa futura, porém cuja realização não se pode ter certeza e a segunda parte podemos imaginar como uma enorme tempestade, que não sessa e nunca sessará, que impede de chegar ao topo da montanha. Neste primeiro momento acompanhamos a crescente paixão de Werther que a cada dia que passa aumenta seus elogios e a sublime admiração pela amada, e a tempestade podemos ver como a relação já consolidada entre Charlotte e Albert.

A primeira menção que temos de Charlotte é na carta de 16 de junho de 1771, Werther fica completamente extasiado ao vê-la e expressa-a pela primeira vez com sublimes características dizendo que não é "capaz de dizer o quanto ela é perfeita e porque é perfeita; basta dizer que cativou todos os [seus] sentidos" ${ }^{12}$. Os elogios superlativos e o caráter dramático e poético do protagonista é uma das maiores marcas deste romance. 0 que podemos ver é que a atração e desejo, iniciados desde a primeira vez que a viu foram aumentando progressivamente na medida em que a conhecia mais e mais, e identificava nela características que lhe agradavam. Esta objetificação se deu em duas esferas: primeiro a fisiológica quando a vê pela primeira vez e unicamente pelas características físicas inicia seu desejo pelo "espetáculo mais encantador" 13 de toda sua vida. E em segundo momento pelas características particulares do agir. "Tanta simplicidade com tanta compreensão, tanta bondade com tanta firmeza! É a paz de espirito na vida real e no cotidiano" 14.

Schopenhauer chegou a teorizar acerca do amor romântico, e sua metafísica do amor sexual nos ajuda a entender este desenvolvimento crescente da obsessão de Werther por Charlotte. Como nos elucida Schopenhauer (2000), o tamanho da paixão (desejo) será proporcional ao nível de individualização do sujeito por aquele que observa. Os graus da paixão, que vão da mais breve a mais veemente, o que as difere em seus graus é o nível da individualização da escolha. Quanto mais exclusivamente um indivíduo for capaz de sanar um maior leque de nossos desejos, nos causando êxtase e satisfação, maior vai ser o sentimento de atração e desejo por esse indivíduo. Esses desejos são físicos em primeiro estágio: no caso "saúde, a força e a beleza" que serão antes de tudo condicionantes fundamentais para a procriação de filhos naturalmente adequados. E em segundo plano, mas não insignificante: exigências mais especiais que tornam o objeto desejado mais "único" e consequentemente mais "completo e perfeito" para aquele que deseja.

Muitas vezes encarado como uma meta ou superação que salva ou guia o significado de nossa vida, o amor sempre foi um dos temas mais recorrentes e idealizados na história do ocidente. Durante séculos ouviram-se narrativas que conjecturavam um amor absoluto, que

\footnotetext{
estar relacionada com a Vontade. A contemplação artística ou da natureza, percebe os objetos como são em si mesmos: nesta contemplação "desinteressada", sujeito e objeto tornam-se um só, dado que possuem a mesma essência. Neste interim a arte possui o papel de negação do corpo e esquecimento do individuo, que encontra na contemplação do belo uma fuga desta existência sofrível pela mortificação da vontade.

11 DEUS, Schopenhauer e o sofrimento, 119.

12 GOETHE, Os sofrimentos do jovem Werther, p 30. No texto original Werther fala em primeira pessoa "meus sentidos", a alteração foi feita por questão estilística do texto.

13 Idem, Ibidem, 32.

14 Idem, Ibidem, 30.
} 
destinavam o homem ao encontro ou busca de uma alma gêmea que ordenaria o sentido de sua existência. Com o decorrer da história, as concepções metafísicas de mundo e as grandes narrativas foram sendo desacreditadas, provocando o surgimento de novas formas de pensar e negar qualquer alusão a idealismos românticos. Podemos também incluir neste hall de pensadores "desiludidos" o próprio Schopenhauer. No romance de Goethe é evidente o quão Werther deseja Charlote. Porém, por que tal desejo se destaca de todos a ponto provocar seu próprio suicídio? Segundo o próprio Schopenhauer por um dos maiores sentimentos de querer da existência: a preservação da espécie.

Todo enamorar-se, por mais etéreo que possa parecer, enraíza-se unicamente no impulso sexual, e é apenas um impulso sexual mais bem determinado, mais bem especializado e mais bem individualizado no sentido rigoroso do termo. [...] 0 impulso sexual [...] ao lado do amor à vida, mostra-se como a mais forte $\mathrm{e}$ ativa das molas propulsoras, absorvendo initerruptamente a metade das forças e pensamentos da parte mais jovem da humanidade. É ele a meta final de quase todo esforço humano ${ }^{15}$.

Se a vontade de vida se manifestasse somente como simples instinto de conservação pessoal, haveria ali somente uma afirmação do fenômeno individual, devido o tempo muito curto de sua duração natural. Os sofrimentos e as penalidades de tal vida seriam medíocres, e a vida seria, assim, fácil e serena. Mas, ao contrário, a vontade deseja a vida de forma absoluta e constante, ao mesmo tempo em que se manifesta sobre a forma de impulso sexual, tendo em vista toda uma série infinita de gerações ${ }^{16}$.

Schopenhauer desenvolveu uma concepção naturalista de amor que, apesar de ainda estar submetida a uma força metafísica, foge dos moldes românticos até então. Schopenhauer nos apresenta uma percepção do amor que é considerado unicamente como um artificio da espécie para perpetuar na existência.

O mais importante a se destacar neste momento é o caráter da soberania da vontade acerca da racionalidade da escolha que Schopenhauer atribui principalmente as paixões. 0 filósofo retira da equação a finalidade do amor como busca por felicidade ou completude existencial e os veem apenas como dois indivíduos sendo impulsionados pela vontade da espécie. Quando nos atraímos um pelos outros, nesta relação não se encontra o desejo de dois indivíduos, mas de pelo menos três, sendo o terceiro a criança que a Vontade da espécie deseja gerar. Para Schopenhauer, já devemos considerar como o primeiro instante do nascimento de um bebê o momento em que seus pais começarem a se interessar um pelo outro, pois todo este interesse só está ocorrendo para a existência daquele que prosseguirá na próxima geração.

0 homem que ama não pertence a si mesmo, pois seus desejos deixam de ter a si mesmo como finalidade. Ele não quer mais como indivíduo, ele quer como espécie. 0 amor é essa contradição, pois através da paixão o individuo, forçosamente, passa a pensar mais no outro do que em sí, mas ainda sim, apesar de ter a sensação de realização no bem de si, o amor é um bem da espécie, uma vontade muito maior que a do individuo. A questão é que a natureza implanta tal sentimento de satisfação irracional e totalmente instintiva nos indivíduos para que, enquanto acham que estão cumprindo suas finalidade e realizações, estão servindo de fato as finalidades da espécie. A natureza fornece uma "ilusão, em virtude da qual aparece como um bem para ele mesmo, o que é de fato um bem só para espécie, de modo que ele a serve enquanto pensa servir a si mesmo" 17.

\footnotetext{
15 SCHOPENHAUER, Metafísica do amor, metafísica da morte, 7.

16 SCHOPENHAUER, Da afirmação da vontade de vida, 150.

17 SCHOPENHAUER, Metafísica do amor, metafísica da morte, 16.
} 
Aqui, portanto, como todo instinto, a verdade assume a figura da ilusão, para garantir sobre a vontade [...] fazendo-o crer que encontrará nos braços de uma mulher, cuja beleza lhe agrada, um gozo maior do que nos braços de uma outra qualquer; ou que direciona exclusivamente para um único individuo, convencendo-o com firmeza que a sua posse lhe daria uma felicidade extrema ${ }^{18}$.

Por mais sublime que possa parecer tal admiração, Para Schopenhauer, isto nada mais é do que o desejo sexual querendo se manifestar e possuir o outro corpo para manutenção da espécie. "A concepção naturalista schopenhauriana sobre amor, de um caráter marcadamente biologista, considera os amantes como meros bonecos do interesse de reprodução da espécie" 19. Esta visão acerca do amor, principalmente em nossa cultura, apesar dos chamados tempos líquidos, ainda é vista como demasiadamente fatalista, entretanto, tem uma questão que didaticamente pode nos levar a corroborar com Schopenhauer: 0 que é mais preferível? A reciprocidade do sentimento ou a posse do corpo? Segundo Schopenhauer, "a posse do corpo, isto é, o gozo físico" 20.

A certeza daquela [correspondência amorosa] não pode de modo algum consolar a ausência deste [gozo físico]: antes, em tal situação, muitos já se suicidaram. Em contra partida, pessoas fortemente enamoradas, se não podem obter a correspondência amorosa contentam-se com a posse.

Apesar de todas as declarações e odes aos sentimentos e a superioridade das sublimes subjetividades que a história evoca durante toda sua narrativa através de seu protagonista, ao mesmo tempo, o comportamento do jovem Werther corrobora com Schopenhauer, ao mostrar que todo o sofrimento se dava única e exclusivamente pela impossibilidade de poder satisfazer suas vontades sexuais com a amada. Apesar do mesmo dizer que "todos os desejos se calam em sua presença" 21 , unicamente a presença da mesma não lhe era suficiente. Algo que é válido observar é que apesar da existência de eventuais elogios a seu corpo e aparência física, em todas as suas cartas, o que Werther evoca como principais motivadores de seus encantos eram as particularidades intelectuais, morais e do bom juízo estético. Porém todos estes atributos, que ele incessantemente menciona como os pilares da beleza de Charlotte, ele detinha a possibilidade de desfrutar, entretanto, não foram o suficiente para se sentisse satisfeito.

É evidente a boa amizade que eles possuem. Uma relação de mútua compreensão e compaixão, de recíproca admiração intelectual e de momentos sublimes. Em alguns momentos podemos até nos questionarmos acerca da possibilidade de Charlotte também sentir algo por Werther, tendo como único motivo de não aceitar tal relação seu compromisso já estabelecido com Alberto. Ou seja, apesar de evocar como última das qualidades de interesse o corpo e o sexo, e ter acesso a todas as outras qualidades que evidencia admirar, é justamente pela impossibilidade de cópula, a única coisa que não pode ter, que motivo seu suicidio. O que nos leva a corroborar com Schopenhauer, o amor não se realiza na satisfação do intelecto, ou na lógica da razão o amor se dá na posse do corpo, em que todos os atributos além-carne são ilusões para justificar a razão o direcionamento de esforços para o seu principal propósito da Vontade: o sexo. Como nos elucida o próprio Werther: "Centenas de vezes já estive prestes a apertá-la em meus braços! Deus Todo-Poderoso sabe o que significa

\footnotetext{
18 Idem, Ibidem, 9.

19 BARRENECHEA, Duas perspectivas sobre o amor: Platão e Schopenhauer, 138.

20 SCHOPENHAUER, Metafísica do amor, metafísica da morte, 10.

21 GOETHE, Os sofrimentos do jovem Werther, 56.
} 
ver tanta amabilidade e não poder tocá-la; e tocar, contudo, é o impulso mais natural da humanidade." 22.

Como vemos na carta de 3 de setembro de 1772, a indignação dele nas curtas quatro linhas é o fato de que outra pessoa pode desejá-la, mas vamos que o problema e a dor de Werther é em essência, não o fato de que existem outras pessoas desejando-a, mas sim porque ele é aquele que deseja e não possui acesso consentido ao corpo da amada. Tal condição: não apenas não ter o que deseja, mas ver o que deseja sendo possuído por outrem é outro agravante ao sofrimento de Werther, que como bem evidencia na carta de 30 de julho de 1771, "mesmo que ele fosse o melhor e o mais generoso dos homens e eu estivesse disposto a me submeter a ele em todos os aspectos, seria insuportável vê-lo na minha frente em posse de tanta perfeição" 23. E como bem nos elucida Schopenhauer em sua metafísica do amor, "a perda da amada para um rival [é] uma dor que supera qualquer outra, justamente porque é de tipo transcendente"24.

\section{O suicidio de Werther: Vontade de morrer ou vontade de viver?}

Em 21 de dezembro de 1772; um ano, seis meses e alguns dias após escrever sua primeira carta para Wilhelm e dizer ao amigo que encontrou o amor de sua vida, Werther decidiu findar definitivamente a própria existência pelo mesmo amor. Curiosamente, como podemos ver no romance, Werther apesar de protagonizar a trágica cena, não realizou seu suicidio de forma pessimista ou banhada a choros, mas sim carregado de certo otimismo, esperança e talvez, até com um sentimento de paz ${ }^{25}$.

Que importa que Albert seja o seu marido? Marido! Seria apenas neste mundo... e neste mundo seria um pecado amá-la, querer arrancá-la dos braços dele? Pecado? Está bem, e vou punir-me por isso; saboreei esse pecado em toda a sua volúpia celestial, o meu coração sorveu a força e o balsamo da vida. Desde este momento você é minha! Minha, ó Lotte! Vou na frente! Vou ter com o meu Pai, com o seu Pai. Quero me queixar com Ele e, até você chegar, ele irá me consolar, voarei ao seu encontro para agarrá-la e ficarei ao seu lado na presença do infinito. Não estou sonhando, nem delirando! Perto do túmulo vejo tudo com mais clareza. Nós continuaremos existindo! Vamos nos ver novamente! Ver a sua mãe! Vou vê-la, encontra-la, ah, e abrir meu coração para ela! Sua mãe, a sua imagem perfeita ${ }^{26 !}$

Wilhelm, pela última vez vi os campos, a floresta e o céu. Adeus a você também! Querida mãe, perdoe-me! Console-a, Wilhelm! Que Deus abençoe vocês! Todas as minhas coisas estão em ordem. Adeus! Tornaremos a nos ver, $e$ mais alegres 2728.

\footnotetext{
22 Idem, ibidem , 120, grifo nosso.

23 Idem, ibidem, 60.

${ }^{24}$ SCHOPENHUAER, Metafísica do amor, metafísica da morte, 40.

25 O flerte do protagonista com o ideal suicida já aparece no romance em uma conversa com o Albert, descrita na carta de 12 de agosto de 1771. Albert repreende e condena o ato suicidio como um exagerado momento de insanidade. Werther, por outro lado, acredita que a morte pode ser sim uma cura para o sofrimento da vida e defende a honra daqueles que se suicidaram.

${ }^{26}$ GOETHE, Os sofrimentos do jovem Werther, 166-167, grifo nosso

${ }^{27}$ Idem, Ibidem, 171, grifo nosso.

${ }^{28}$ Devemos observar como Werther vê a morte do corpo como libertação, não da existência, mas da alma, já que o mesmo explicita sua crença no outro mundo em suas ultimas cartas. Na carta de 16 de Janeiro, Werther faz questão de deixar claro: "por mais de cem vezes já peguei uma faca para dar razão a este coração amargurado [...] Sinto-me assim muitas vezes e gostaria de abrir uma veia que me desse à liberdade eterna" (Goethe, Os
} 
Tal cenário nos orienta ao questionamento feito no início desta secção: o suicidar-se é uma vontade de viver ou de morrer? A primeira vista tal pergunta pode parecer banal, sendo ordinário que a primeira reação de resposta no senso comum seja dizer que, claramente, quando retiramos nossa vida de forma voluntária é porque há uma vontade de morrer e que este seria o caso do jovem Werther, estava triste e, portanto, decidiu retirar a própria vida. Entretanto, Schopenhauer possui um ponto de vista diferente acerca deste fenômeno, que se encontra intimamente correlacionada e ocasionada por suas considerações acerca da metafísica da Vontade e do sofrimento.

Para Schopenhauer, como bem caracteriza no parágrafo 69 d'O mundo, o suicidio não representa uma negação da vontade de viver, mas sim uma de suas maiores afirmações ${ }^{29}$. "0 suicida quer a vida; porém está insatisfeito com as condições sob as quais a vive.” (W I, 504). Ao destruir o próprio corpo, não é ao querer viver que ele renuncia, mas ao sofrimento incutido na vida. 0 suicida, como o próprio Werther nos mostra, deseja afirmar a sua vontade, porém, quando existem barreiras (sofrimentos) intransponíveis ou fora de alcance de serem removidas, ele, em fuga da dor, destrói o próprio corpo. Pois "quando se chega ao ponto em que os horrores da vida superam os horrores da morte, o homem dá um fim à sua vida"30.

Com efeito, quando sofremos em nosso corpo com grande intensidade, ou de forma contínua, ficamos indiferentes a todas as demais aflições: somente importa o nosso restabelecimento. Do mesmo modo, os intensos sofrimentos espirituais nos fazem insensíveis aos corporais: nós os desprezamos. Quando em algum sonho terrível, o medo alcança o mais alto grau, o mesmo nos faz despertar e desaparece o monstro da noite. 0 mesmo ocorre no sonho da vida, quando o mais alto grau de angústia nos obriga a interrompê-la ${ }^{31}$.

O que vemos é que o sofrimento intenso é aquilo que direciona o nosso querer a eliminação de nossa ponte de acesso ao mundo, vulgo corpo e que este sofrimento é intimamente ligado ao tamanho do querer. Sendo no caso de Werther, para Schopenhauer, um tipo de sofrimento específico que também é um dos mais intensos: a impossibilidade de realização da vontade amorosa ${ }^{32}$. Como nos aponta Schopenhauer, a perda da pessoa que se

sofrimentos do jovem Werther, p. 101). O que destacamos é que esta crença não apenas reproduz a concepção schopenhauriana do corpo como prisão de sofrimento, mas toda a filosofia do corpo do ocidente que se origina com Platão. Ao estabelecer a realidade também de forma dual, colocando o mundo verdadeiro como o mundo inteligível e o mundo falso como o sensível, Platão originou uma linhagem de desprezadores do corpo que tornaram o mundo verdadeiro, o mundo material, uma fábula, como bem especifica Nietzsche $(2014,2017)$, pois, para o discípulo de Sócrates, assim como seu mestre, o mundo que acessamos pelo corpo é enganador, assim como o próprio corpo. Para o filósofo grego, o corpo é a prisão da essência verdadeira do homem: sua alma. Cunha (2015) nos diz que é com essa hierarquização de Platão acerca da superioridade da substância inteligível (alma) sobre o corpo, deixando "o mundo sensível, desprovido de ser, relegado à relatividade e à imperfeição." que vemos o início de desta saga de subjugação do corpo. É neste mesmo caminho de condenação do corpo, junto a suas influências orientais, que Schopenhauer fundamenta sua filosofia, o que leva pensadores como Nietzsche formarem grandes críticas a sua filosofia - Destaco a obra de Salviano (2013), que de forma primorosa sistematiza a crítica nietzschiana a Schopenhauer - e que consequentemente também criticaria veementemente o "platonismo" de Werther. Em seu suicidio o protagonista evoca diversas vezes seu contentamento pela vida após a morte. Se Schopenhauer nos explica a escolha como fuga do sofrimento, Nietzsche $(2014,2017)$ vai mais fundo e vê o mesmo como efeito da cultura ocidental socrático-platônica-cristã que de forma covarde criou e supervalorizou o outro mundo, para que os fracos de "espirito" não tivessem que se afirmar neste.

29 Apesar de fornecer criticas contra a criminalização e ofensas ao ato suicida, Schopenhauer não o encoraja e nem o vê como a mais apropriada ação, pois, sendo o suicidio ainda uma afirmação do querer, ele, através da destruição do corpo, é um recurso ilusório contra o ciclo do sofrimento e um afastamento do verdadeiro bem e ação moral: a negação e mortificação da vontade.

30 SCHOPENHAUER, Sobre o suicidio, 438.

31 Idem, Ibidem, 438.

${ }^{32}$ Algo curioso que podemos observar na narrativa é que para Werther os sentimentos de paixões avassaladoras podem ser legitimadores da violência, tanto a violência contra si (suicidio) como aquela que aflige o outro 
ama é um sofrimento que ultrapassa todos os outros, pois não atinge unicamente o individuo em sua ilusória individualização no mundo, mas, atinge antes de tudo a vontade da espécie, que tem sua missão fracassada, "a renúncia da amada, é o maior de todos os sacrifícios. - Um herói se envergonha de todas as lamúrias, menos as amorosas; porque nelas não é ele, mas a espécie que lamenta" 33 .

\section{Para concluir, em resumo...}

Na história da filosofia ocidental, desde Platão, não é incomum o uso da literatura, ou seja, escritos focadas na narração de uma história de um personagem ou trama, para uma melhor explicitação das ideias filosóficas. Os romances tornam-se respostas personificadas das perguntas que podem surgir após um puro tratado sistemático exposto e talvez, também suas respostas. Por exemplo, Albert Camus, após a escrita de seu ensaio $O$ mito de Sísifo, escreveu não apenas o romance $O$ estrangeiro como também um peça (Os justos) para melhor explicar suas ideias. Alguns séculos antes Voltaire escreveu $O$ cândido como uma forma de representar suas críticas ao conformismo. Apesar de mais particular, o próprio Nietzsche em Assim falava Zaratustra realiza tal intersecção.

Schopenhauer, apesar de ter ilustrado suas teorias metafísicas com inúmeras situações e condições da vida cotidiana para melhor entendimento de seus leitores ${ }^{34}$, ao contrário dos anteriormente citados, não chegou a se dedicar a escrita de narrativas para tal proposta. Ainda que tenha se abstido a esta produção, isto não é um impedimento para mostrarmos como sua filosofia parecer ser ilustrada em produções de outros literatos. Por exemplo, a presença de sua filosofia na obra de Machado de Assis: seja no niilismo e pessimismo, como nos mostra Garcia (1979) ou na metafísica do amor como nos aponta Dias (2005), nos escritos de Clarice Lispector e a possível intersecção com a estética de Schopenhauer como nos evidenciam Veloso e Rocha (2016) ou até mesmo nas aproximações com Fiódor Dostoiévski acerca de questões da moralidade, ascetismo e racionalidade, como Calou (2018) vem nos apresentando nestes últimos anos. Nosso objetivo aqui foi, então, realizar a conexão de alguns aspectos da filosofia de Schopenhauer com a narrativa d'Os sofrimentos do jovem Werther de Goethe.

Para além da estilística do texto, a progressão da história e a notável expressão romântica e poética das cartas que dão corpo ao romance, uma das, talvez a maior, característica marcante do mesmo é o seu grand finale: o suicidio do protagonista ${ }^{35}$. 0 que vemos durante a história é a gradação crescente do sofrimento de Werther em não ter sua

(assassinato). "Sabem expor com exatidão as razões porque ela [ação suicida] aconteceu e porque tinha de acontecer? Se soubessem tudo isso, não seriam tão apressados em seus julgamentos [...] Quem vai atirar a primeira pedra no marido ultrajado, que numa fúria justa sacrifica a sua mulher infiel e seu infame sedutor?" (GOETHE, Os sofrimentos do jovem Werther, 66). É possível ver também uma romanização do estupro. Após conhecer a história de um rapaz em embriagado de paixão atacou à força a mulher que desejava, sem seu consentimento, Werther admirado por tamanha entrega do sujeito a seus sentimentos comenta: "não tenho nem a metade da coragem, nem a metade da determinação desse pobre infeliz, com o qual quase não me atrevo a comparar-me" (Idem, ibidem, 112)

${ }^{33}$ SCHOPENHAUER, Metafísica do amor, Metafísica da Morte, 40.

${ }^{34}$ Apesar de ter sistematizado sua Filosofia na sua magno opus ( $O$ mundo como Vontade e Representação) e ser altamente reverenciado pela mesma, Schopenhauer só foi obter fama e popularidade já no fim da vida, em 1851 , com a escrita do Parerga e Paralipomena , que tomando como ponto de partida sua filosofia desenvolvida n' $O$ mundo e opiniões particulares sobre a cultura do ocidente, escreveu inúmeros textos diversos sobre cotidianidades e assuntos diversos.

350 suicidio de Werther foi um marco tão grande da literatura mundial que acabou influenciando a população em geral, aumentando os índices de suicídios por desesperança da época, o que fez com que o livro fosse banido em alguns locais. 
amada, o que direciona a findar sua própria vida. Tomamos, assim, o suicidio como principal horizonte de análise do texto, pois ao entender os mecanismos de suas motivações podemos abstrair considerações sobre outros fenômenos, como sofrimento, amor e desejo e formar uma compreensão schopenhauriana de forma geral acerca da narrativa.

O sofrimento, como conclui Schopenhauer, se apresenta não apenas como todo momento de impossibilidade de afirmação da vontade, sendo o mesmo gradual ao nível da proporção do individuo para com aquilo que quer. E sendo o sofrimento todo impedimento de afirmação da vontade, vemos que Albert, marido de Charlotte, é a encarnação deste sofrimento para Werther. Não são poucas as vezes que Werther demostra o desejo do sumiço, morte $^{36}$, ou assassinato ${ }^{37}$ do personagem para ter seu caminho livre.

Ainda como nos explica Schopenhauer: a atração e desejo sexual é o mais forte dos quereres, pois não se trata apenas um querer da nossa ilusória individualização da Vontade (essência una e intransponível do mundo), mas sim é um querer de toda a espécie que deseja se perpetuar. E como evidenciamos no texto, por mais que a obra seja uma antologia de declarações de amor, que elevam e elogiam os atributos metafísicos do espirito: inteligência, honestidade, inspiração estética, bom gosto, etc. Tudo a tragédia no texto se dá pela não realização da posse do corpo do outrem. "Ele quer amar e possuir; fundir-se e multiplicar-se" 38.

$\mathrm{Na}$ impossibilidade de tal, vendo o amigo viver a vida que quer viver, Werther opta por eliminar a própria vida para não ter lidar com tal dor. Sendo a morte nestes momentos uma condição que apazigua todos os conflitos e suas dores, que no romance são causados pela fatalidade de se ver eternamente sem amor. O que também ilustra a concepção de Schopenhauer acerca do suicidio, já que o mesmo não enxerga o fenômeno como uma vontade de morte, mas sim de vida. Pois é o suicidio não uma renuncia a vida, mas uma busca pela eliminação do sofrimento, sofrimento este que é tão maior quanto maior é o desejo, e sendo um dos maiores desejos da humanidade o sexual, as dores causadas por esta vontade não afirmada se enquadra como uma das mais torturantes, sendo o suicidio um querer viver frustrado, e a morte voluntária em nada renuncia a vontade, mas justamente por ela o corpo se autodestrói. "É a paixão sofrida até a mais absoluta destruição, até a aniquilação das forças vitais" 39 .

Claramente não é possível cogitar a possibilidade da influência de Schopenhauer na escrita dos Sofrimentos do jovem Werther, como no caso de algumas obras de Machado de Assis, por exemplo, já que o livro foi escrito em 1774, 14 anos antes do nascimento do nosso filósofo de Frankfurt. Entretanto, tendo discorrido sobre as intersecções ao longo do texto, creio ter realizado de forma sistemática e consistente a forma relativamente precisa como o romance epistolar de Goethe ilustra a metafísica do sofrimento, do amor e do suicidio presentes na filosofia de Arthur Schopenhauer.

\section{Referências}

\footnotetext{
36 “Quando me perco em sonhos, não consigo resistir a essa ideia: e se Albert morresse?" Carta de 21 de agosto de 1772. (GOETHE, Os sofrimentos do jovem Werther, 109).

37 "Já fui muitas vezes invadido pela fúria de... matar o seu marido..." Carta de 21 de dezembro de 1772. (GOETHE, Os sofrimentos do jovem Werther, 149).

38 PASCHOAL, Werther ou o romance do ímpeto destrutivo, 181.

${ }^{39}$ Idem, Ibidem, 181.
} 
BARROS, Eduardo Portanova. Michel Maffesoli: a pós-modernidade se orienta para "algo de anarquista". Tradução: Ana Taís Barros. In: Em Questão, v. 19, n.2, p. 12-19, 2013. Disponível em: <seer.ufrgs.br/EmQuestao/article/view/41958/31044>. Acesso: 19 jun. 2020.

BARRENECHEA, Miguel Angel. Duas perspectivas sobre o amor: Platão e Schopenhauer. In: Revista Lampejo, no 7, p. 128-143, 2015. Disponível em: <revistalampejo.apoenafilosofia. org/?page id=712>. Acesso em: 05 de jun. 2020.

BRUM, José Thomaz. O pessimismo e suas vontades: Schopenhauer e Nietzsche. Rio de Janeiro: Rocco, 1998.

CACCIOLA, Maria Lucia Mello e Oliveira. Schopenhauer e a questão do dogmatismo. São Paulo: EDUSP, 1994.

CALOU, Ângela Lima. O conceito de razão em Arthur Schopenhauer e Fiódor Dostoiévski, 2018. Disponível em: <anpof.org/portal/index.php/pt-BR/agenda-encontro-2018/item/559categoriaagenda2018/17781-o-conceito-de-razao-em-arthur-schopenhauer-e-fiodordostoievski>. Acesso em 08 de jul. 2020.

DIAS, Rosa Maria. "O autor de si mesmo": Machado de Assis leitor de Schopenhauer. In: Kriterion: Revista de Filosofia, Belo Horizonte, no 112, p. 382-392, 2005. Disponível em: <doi.org/10.1590/S0100-512X2005000200020 >. Acesso em: 08 de mar. 2020.

DEUS, Flávio Rocha de. Schopenhauer e o sofrimento: uma aproximação com as quatro nobres verdades do Budismo. In: Occursus - Revista de Filosofia, v. 3, n. 1, p. 113-121, 2018. Disponível

em:

<http://seer.uece.br/?journal=0ccursos\&page=article\&op=view\&path\%5B\%5 $\quad \mathrm{D}=3303>$. Acesso: 17 de mar. 2020.

FREITAS, Nanci de. A conjunção de Fiesco em Gênova: história, tempestade e ímpeto na cena do jovem Schiller. In: Urdimento: Revista de Estudos em Artes Cênicas, n. 6, p. 20-33, 2004.

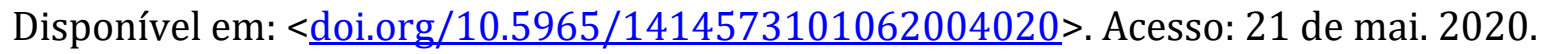

GARCIA, Ana Lúcia Gazolla. Schopenhauer e Machado de Assis. In: Romance Notes, vol. 19, n. 3, pp. 327-334, 1979. Disponível em: <jstor.org/stable/43801585>. Acesso: 25 de mar. 2020.

GOETHE, Johann Wolfgang von. Os sofrimentos do jovem Werther. Tradução, notas e posfácio: Erlon José Paschoal. 8a ed. São Paulo: Estação Liberdade, 2017.

LOWY, Michel; SAYRE, Robert. Revolta e melancolia: o romantismo na contracorrente da modernidade. São Paulo: Boitempo, 2015.

MAYOS, Gonçal. Ilustración y Romanticismo; Introducción a la polémica entre Kant y Herder. Barcelona: Editorial Herder, 2004. Disponível em: <ub.edu/histofilosofia/gmayos old/PDF/IluminismoFrenteRomantPort.pdf>. Acesso: 21 de mai. 2020.

NIETZSCHE, Friedrich. Assim falou Zaratustra: um livro para todos e para ninguém. Tradução: Carlos Duarte e Anna Duarte. São Paulo: Martin Claret, 2014.

NIETZSCHE, Friedrich. Crepúsculo dos ídolos. Tradução, notas e posfácio de Paulo César de Souza. São Paulo: Companhia de Bolso, 2017.

PASCHOAL, Erlon José. Posfácio "Werther ou o romance do ímpeto destrutivo". In: GOETHE, Johann Wolfgang von. Os sofrimentos do jovem Werther. Tradução: Erlon José Paschoal. 8ª ed. São Paulo: Estação Liberdade, 2017.

SALVIANO, Jarlee Oliveira Silva. Labirintos do nada: A crítica de Nietzsche ao Niilismo de Schopenhauer. São Paulo: Editora da Universidade de São Paulo, 2013. 
SCHOPENHAUER, Arthur. Metafísica do amor, Metafísica da morte. Tradução: Jair Barboza. São Paulo: Martins Fontes, 2000.

SCHOPENHAUER, Arthur. O mundo como vontade e como representação - $1^{\mathrm{o}}$ tomo (W I). Tradução: Jair Barboza. São Paulo: Editora UNESP, 2005.

SCHOPENHAUER, Arthur. Da afirmação da vontade de vida. Tradução: Felipe Cardoso Martins Lima, Marcelo Prates de Souza e Edy Klévia Fraga de Souza In: Revista Voluntas: Estudos sobre Schopenhauer, v. 1, n. 2, pp. 150-154, 2010.

SCHOPENHAUER, Arthur. Sobre o suicídio. Tradução e notas de Rosana Jardim Candeloro. Griot: Revista de Filosofia, Amargosa, v.16, n.2, p. 435-439, 2017.

SOUZA, Mauro Araujo de. Alma em Nietzsche: a concepção de espírito para o filósofo alemão. São Paulo: Leya, 2013.

VELOSO, Layane; ROCHA, Fábio Libório. A coisa irracional: Schopenhauer e Clarice Lispector. In: Revista Húmus, São Luís, v. 6, n. 16, p. 45-59, 2016. Disponível em: <periodicoseletronicos.ufma.br/index.php/revistahumus/article/view/4567>. Acesso: 08 de jul. 2020. 